Appl. Set-Valued Anal. Optim. 3 (2021), No. 2, pp. 193-202

Available online at http://asvao.biemdas.com

https://doi.org/10.23952/asvao.3.2021.2.04

\title{
CONVERGENCE THEOREMS FOR A FIXED POINT OF $\eta$-DEMIMETRIC MAPPINGS IN BANACH SPACES
}

\author{
NASEER SHAHZAD ${ }^{1, *}$, HABTU ZEGEYE ${ }^{2}$ \\ ${ }^{1}$ Department of Mathematics, King Abdulaziz University, Jeddah 21589, Saudi Arabia \\ ${ }^{2}$ Department of Mathematics and Statistical Sciences, \\ Botswana International University of Science and Technology, Palapye, Botswana
}

\begin{abstract}
The purpose of this paper is to propose and investigate an algorithm for solving a fixed point of $\eta$-demimetric mappings. We establish the strong convergence of the proposed algorithm under some mild conditions in Banach spaces. We apply these results to obtain new strong convergence theorems which are connected with the $\eta$-demimetric fixed point problems in Hilber/Banach spaces.
\end{abstract}

Keywords. Fixed point; $\eta$-Demimetric mapping; Monotone mappings; Strong convergence; Uniformly convex spaces.

\section{INTRODUCTION}

Let $C$ be a nonempty subset of a real smooth Banach space $E$ with its dual $E^{*}$. Let $\eta \in$ $(-\infty, 1)$ and $p \in(1, \infty)$. A mapping $T: C \rightarrow E$ with $F(T) \neq \emptyset$ is called $\eta$-demimetric (see, $[1,2])$ if, for any $x \in C$ and $x^{*} \in F(T)$, there exists $j_{E}^{p}(x-T x) \in J_{E}^{p}(x-T x)$ such that

$$
\left\langle x-x^{*}, j_{E}^{p}(x-T x)\right\rangle \geq \frac{1-\eta}{2}\|x-T x\|^{p},
$$

where $J_{E}^{p}$ is the generalized duality mapping from $E$ into $2^{E^{*}}$ defined by

$$
J_{E}^{p}(x):=\left\{f \in E^{*}:\langle x, f\rangle=\|x\|^{p},\|f\|=\|x\|^{p-1}\right\} .
$$

We note that, in (1.2), if $p=2$, then $J_{E}^{2}=J_{E}$ is called the normalized duality mapping. It is well-known (see, for example, $([3,4])$ that if $E$ is smooth, then $J_{E}^{p}$ is one-to-one and single valued and it also satisfies

$$
J_{E}^{p}(x)=\|x\|^{p-2} J_{E}(x), \quad x \neq 0 .
$$

Furthermore, if $E$ is uniformly smooth, then $J_{E}^{p}$ is uniformly continuous on bounded subsets of $E$; if $E$ is reflexive, strictly convex and smooth Banach space, then $J_{E^{*}}^{q}: E^{*} \rightarrow 2^{E}$ is one-to-one, surjective, and it is the duality mapping from $E^{*}$ into $E$. Thus, $J_{E}^{p} J_{E^{*}}^{q}=I_{E^{*}}$ and $J_{E^{*}}^{q} J_{E}^{p}=I_{E}$, where $q$ is a real number satisfying $\frac{1}{p}+\frac{1}{q}=1$ (see, e.g., $[5,6]$ ). We also note that if $E:=H$, a real Hilbert space, then $J_{H}=I$, where $I$ is the identity mapping.

${ }^{*}$ Corresponding author.

E-mail addresses: nshahzad@kau.edu.sa (N. Shahzad), habtuzh@yahoo.com (H. Zegeye).

Received April 6, 2020; Accepted June 19, 2020.

(C)2021 Applied Set-Valued Analysis and Optimization 
We remark that inequality (1.1) is equivalent to

$$
\left\langle x-x^{*}, J_{E}(x-T x)\right\rangle \geq \frac{1-\eta}{2}\|x-T x\|^{2},
$$

for all $x \in C$ and $x^{*} \in F(T)$.

Let $E$ be a reflexive, strictly convex, and smooth Banach space and let $A: E \rightarrow 2^{E^{*}}$ be a maximal monotone mapping with $A^{-1}(0) \neq \emptyset$. Then, for each $x \in E$ and $r>0$, consider the mapping defined by $J_{r}^{A} x:=\{z \in E: 0 \in J(z-x)+r A z\}$ (equivalently, $J_{r}^{A}=\left(I+\left(J_{E}^{p}\right)^{-1} A\right)^{-1}$ : $E \rightarrow E^{*}$ ), which is point-to-point and nonexpansive mapping (see, for example, Proposition 57.5(b) of [7]). Then, the resolvent $J_{r}^{A}$ of $A$ with $A^{-1}(0)$ nonempty is (-1)-demimetric (see, for example, [8]). Let $C$ be a nonempty, closed and convex subset of a strictly convex, reflexive and smooth real Banach space $E$. Let $P_{C}$ be the metric projection of $E$ onto $C$. Then $P_{C}$ is $(-1)$-demimetric (see [9]). Other examples of $\eta$-demimetric mappings in Hilbert spaces are those mappings in a class of demicontractive mappings. A mapping $T: C \rightarrow H$, where $C$ is a subset of a Hilbert space $H$, is called $k$-demicontractive if there exists $k \in[0,1)$ such that

$$
\left\|T x-T x^{*}\right\|^{2} \leq\left\|x-x^{*}\right\|^{2}+k\|x-T x\|^{2},
$$

for each $x \in C$ and $x^{*} \in F(T)$. We note that the class of $k$-demicontractive mappings contains the class of quasi-nonexpansive mappings, that is, $F(T) \neq \emptyset$ and

$$
\left\|T x-T x^{*}\right\| \leq\left\|x-x^{*}\right\|, \text { for all } x \in C, x^{*} \in F(T) .
$$

Several authors have studied various methods for fixed points of $k$-demicontractive mappings (see, for example, $[10,11])$. It was shown in [12] that $k$-demicontractive mappings are $k$ demimetric.

In 2016, Hojo and Takahashi [13] used the shrinking projection method to approximate fixed points of $\eta$-demimetric mappings in Banach spaces. Indeed, they proved the following result.

Theorem 1.1. Let $C$ be a nonempty, closed and convex subset of a uniformly convex and smooth Banach space E. Let $\eta$ be in $(-\infty, 1)$. Let $T: C \rightarrow C$ be an $\eta$-demimetric and demiclosed mapping with with $F(T) \neq \emptyset$. Let $x_{1} \in C, C_{1}=C$ and $\left\{x_{n}\right\}$ be a sequence generated by

$$
\left\{\begin{array}{l}
z_{n}=\alpha_{n} x_{n}+\left(1-\alpha_{n}\right) T x_{n} \\
C_{n}=\left\{z \in C: 2\left\langle x_{n}-z, J_{E}\left(x_{n}-z_{n}\right)\right\rangle \geq(1-\eta)\left\|x_{n}-z_{n}\right\|^{2}\right\} \\
Q_{n}=\left\{z \in C:\left\langle x_{n}-z, J_{E}\left(x_{1}-x_{n}\right)\right\rangle \geq 0\right\} \\
x_{n+1}=P_{C_{n} \cap Q_{n}} x_{1}, n \geq 1
\end{array}\right.
$$

where $0 \leq \alpha_{n} \leq a<1$ for some $a \in \mathbb{R}$. Then, the sequence $\left\{x_{n}\right\}$ converges strongly to a point $\widehat{z_{0}} \in F(T)$, where $\widehat{z_{0}}=P_{F(T)} x_{1}$.

We observe that Algorithms (1.3) requires to calculate $C_{n}$ and $Q_{n}$, which are not easy at each iterative step. This leads us to the following question.

Question: Can one obtain an iterative scheme which converges strongly to a fixed point of an $\eta$-demimetric mapping and does not involve the calculation of $C_{n}$ and $Q_{n}$ for each iterative step in Banach spaces?

Motivated and inspired by Hojo and Takahashi [13], we study a new iterative scheme for fixed points of $\eta$-demimetric mappings. We obtain strong convergence of the scheme under some mild conditions in the setting of Banach spaces. Our results provide an affirmative answers to the above question. 


\section{PRELIMINARIES}

A real Banach space $E$ is said to be smooth if $\lim _{t \rightarrow 0} \frac{\| x+t y||-|| x||}{t}$ exists for each $x, y \in S(E):=$ $\{x \in E:\|x\|=1\}$. A space $E$ is called $q$-uniformly smooth if there exist a constant $c>0$ and a real number $q \in(1, \infty)$ such that $\rho_{E}(\tau) \leq c \tau^{q}$, where $\rho_{E}:[0, \infty) \rightarrow[0, \infty)$ is defined by

$$
\rho_{E}(\tau):=\sup \left\{\frac{\|x+y\|+\|x-y\|}{2}-1:\|x\|=1,\|y\|=\tau\right\} .
$$

$E$ is called uniformly smooth if $\lim _{\tau \rightarrow 0} \frac{\rho_{E}(\tau)}{\tau}=0$. A Banach space $E$ is called uniformly convex if and only if $\sigma(\varepsilon)>0$, for every $\varepsilon \in(0,2]$, where $\sigma:(0,2] \rightarrow[0,1]$ is defined by

$$
\sigma(\varepsilon)=\inf \left\{1-\left\|\frac{x+y}{2}\right\|:\|x\|=\|y\|=1 ; \varepsilon=\|x-y\|\right\} .
$$

Let $p>0$. Then, $E$ is said to be $p$-uniformly convex if there exists a constant $c>0$ such that $\sigma(\varepsilon) \geq c \varepsilon^{p}$, for all $\varepsilon \in(0,2]$.

We remark that $E$ is uniformly smooth if and only if $E^{*}$ is uniformly convex (see [14]). We also know that $E$ is $q$-uniformly smooth if and only if its dual $E^{*}$ is $p$-uniformly convex. The examples of such spaces are the $L_{p}, l_{p}$ and $W_{m}^{p}$ spaces for $1<p<\infty$ (see, for example, [15]), where

$$
L_{p}\left(l_{p}\right) \text { or } W_{m}^{p} \text { is }\left\{\begin{array}{l}
2 \text {-uniformly smooth and } p \text {-uniformly convex if } 2 \leq p<\infty \\
2 \text {-uniformly convex and } p \text {-uniformly smooth if } 1<p<2
\end{array}\right.
$$

The following result was proved by $\mathrm{Xu}$ [15] in $q$-uniformly smooth spaces.

Lemma 2.1. Let $x, y \in E$. If $E$ is $q$-uniformly smooth, then there is a $c_{q}>0$ such that

$$
\|x+y\|^{q} \leq\|x\|^{q}+q\left\langle y, J_{E}^{q}(x)\right\rangle+c_{q}\|y\|^{q} .
$$

Let $1<q, p<\infty$ with $\frac{1}{p}+\frac{1}{q}=1$. The Bregman distance with power $p$ is defined by

$$
\phi_{p}(x, y)=\frac{1}{q}\|x\|^{p}-\left\langle J_{E}^{p} x, y\right\rangle+\frac{1}{p}\|y\|^{p} .
$$

Lemma 2.2. [16] Let $E$ be a real smooth and uniformly convex Banach space and let $\left\{x_{n}\right\}$ and $\left\{y_{n}\right\}$ be two sequences of $E$. If either $\left\{x_{n}\right\}$ or $\left\{y_{n}\right\}$ is bounded and $\phi_{p}\left(x_{n}, y_{n}\right) \rightarrow 0$ as $n \rightarrow \infty$, then $x_{n}-y_{n} \rightarrow 0$ as $n \rightarrow \infty$.

Let $C$ be a nonempty, closed and convex subset of a smooth and strictly convex real Banach space $E$. The Bregman projection is the unique minimizer of the Bregman distance [17] given by

$$
\Pi_{C} x=\arg \min _{y \in C} \phi_{p}(x, y), x \in E .
$$

If $E=H$, a Hilbert space, then the Bregman projection $\Pi_{C}$ reduces to the metric projection $P_{C}$ from $H$ onto $C$.

We remark that the Bregman projection has the following properties (see [3]):

$$
\left\langle J_{E}^{p}(x)-J_{E}^{p}\left(\Pi_{C} x\right), z-\Pi_{C} x\right\rangle \leq 0, \forall z, \in C,
$$

and

$$
\phi_{p}\left(\Pi_{C} x, z\right) \leq \phi_{p}(x, z)-\phi_{p}\left(x, \Pi_{C} x\right), \forall z \in C .
$$


Let $V_{p}: E^{*} \times E \rightarrow[0,+\infty)$ be defined by

$$
V_{p}(\bar{x}, x)=\frac{1}{q}\|\bar{x}\|^{q}-\langle\bar{x}, x\rangle+\frac{1}{p}\|x\|^{p}, \forall x \in E, \bar{x} \in E^{*} .
$$

Then, we observe that $V_{p}$ is characterized by

$$
V_{p}(\bar{x}, x)=\phi_{p}\left(\left(J_{E}^{p}\right)^{-1}(\bar{x}), x\right),
$$

for all $x \in E$ and $\bar{x} \in E^{*} . V_{p}$ is convex in the first variable, that is, for all $z \in E$,

$$
\phi_{p}\left(\left(J_{E}^{p}\right)^{-1}\left(\sum_{i=1}^{N} t_{i} J_{E}^{p}\left(x_{i}\right)\right), z\right) \leq \sum_{i=1}^{N} t_{i} \phi_{p}\left(x_{i}, z\right),
$$

where $\left\{x_{i}\right\}_{i=1}^{N} \subset E$ and $\left\{t_{i}\right\}_{i=1}^{N} \subset(0,1)$ with $\sum_{i=1}^{N} t_{i}=1$ (see, e.g., [18]). Moreover, by the subdifferential inequality, we have

$$
V_{p}(\bar{x}, x) \leq V_{p}(\bar{x}+\bar{y}, x)-\left\langle\bar{y},\left(J_{E}^{p}\right)^{-1}(\bar{x})-x\right\rangle,
$$

for all $x \in E$ and $\bar{x}, \bar{y} \in E^{*}$ (see also $[19,20]$ ).

We also need the following lemmas.

Lemma 2.3. [21] Let $\left\{a_{n}\right\}$ be a sequence of real numbers such that there exists a subsequence $\left\{n_{i}\right\}$ of $\{n\}$ such that $a_{n_{i}}<a_{n_{i}+1}$ for all $i \in \mathbb{N}$. Then there exists an increasing sequence $\left\{m_{k}\right\} \subset$ $\mathbb{N}$ such that $m_{k} \rightarrow \infty$ and the following properties are satisfied by all (sufficiently large) numbers $k \in \mathbb{N}: a_{m_{k}} \leq a_{m_{k}+1}$ and $a_{k} \leq a_{m_{k}+1}$. In fact, $m_{k}$ is the largest number $n$ in the set $\{1,2, \ldots, k\}$ such that the condition $a_{n} \leq a_{n+1}$ holds.

Lemma 2.4. [22] Let $\left\{a_{n}\right\}$ be a sequence of nonnegative real numbers satisfying the following relation: $a_{n+1} \leq\left(1-\alpha_{n}\right) a_{n}+\alpha_{n} \delta_{n}, n \geq n_{0}$, where $\left\{\alpha_{n}\right\} \subset(0,1)$ and $\left\{\delta_{n}\right\} \subset \mathbb{R}$ satisfying the following conditions: $\sum_{n=1}^{\infty} \alpha_{n}=\infty$, and $\limsup _{n \rightarrow \infty} \delta_{n} \leq 0$. Then, $\lim _{n \rightarrow \infty} a_{n}=0$.

Lemma 2.5. [2] Let $C$ be a nonempty, closed and convex subset of a smooth and strictly convex Banach space E. Let $\eta$ be in $(-\infty, 1)$. Let $T$ be an $\eta$-demimetric mapping of $C$ into $E$. Then $F(T)$ is closed and convex

\section{MAin RESUlTS}

Let $C$ be a subset of a real Banach space $E$, and let $T: C \rightarrow E$ be a mapping. The mapping $(I-T)$ is called demiclosed at zero if for a sequence $\left\{x_{n}\right\} \subset C$ such that $x_{n} \rightarrow x$ and $x_{n}-T x_{n} \rightarrow$ 0 , then $x=T x$. Throughout this section, unless otherwise specified, we assume that $p>1$ and $q>1$ satisfying $\frac{1}{p}+\frac{1}{q}=1$, and $\left\{\alpha_{n}\right\} \subset(0, e) \subset(0,1)$ satisfying $\lim _{n \rightarrow \infty} \alpha_{n}=0, \sum_{n=1}^{\infty} \alpha_{n}=\infty$.

We now in a position to prove our main theorem.

Theorem 3.1. Let $C$ be a nonempty, closed and convex subset of a p-uniformly convex and smooth real Banach space $E$. Let $T: C \rightarrow E$ be an $\eta$-demimetric mapping with $F(T) \neq \emptyset$. For arbitrary $x_{0}, u \in C$, define an iterative sequence by

$$
\left\{\begin{array}{l}
y_{n}=\left(J_{E}^{p}\right)^{-1}\left[J_{E}^{p} x_{n}-t_{n} J_{E}^{p}\left(x_{n}-T x_{n}\right)\right], \\
x_{n+1}=\Pi_{C}\left(J_{E}^{p}\right)^{-1}\left[\alpha_{n} J_{E}^{p} u+\left(1-\alpha_{n}\right) J_{E}^{p} y_{n}\right],
\end{array}\right.
$$

where $0<\delta \leq t_{n} \leq \gamma<\left(\frac{(1-\eta) q}{2 c_{q}}\right)^{\frac{1}{q-1}}$, for all $n \geq 0$ and $c_{q}$ is the constant in (2.1). Then $\left\{x_{n}\right\}$ is bounded. 
Proof. Fix $x^{*} \in F(T)$. From (2.2), (3.1) and Lemma 2.1, we obtain

$$
\begin{aligned}
\phi_{p}\left(y_{n}, x^{*}\right)= & \phi_{p}\left(\left(J_{E}^{p}\right)^{-1}\left[J_{E}^{p} x_{n}-t_{n} J_{E}^{p}\left(x_{n}-T x_{n}\right)\right], x^{*}\right) \\
= & \frac{1}{q}\left\|J_{E}^{p} x_{n}-t_{n} J_{E}^{p}\left(x_{n}-T x_{n}\right)\right\|^{q}-\left\langle J_{E}^{p} x_{n}, x^{*}\right\rangle+t_{n}\left\langle J_{E}^{p}\left(x_{n}-T x_{n}\right), x^{*}\right\rangle+\frac{1}{p}\left\|x^{*}\right\|^{p} \\
\leq & \frac{1}{q}\left(\left\|J_{E}^{p} x_{n}\right\|^{q}-q t_{n}\left\langle J_{E}^{p}\left(x_{n}-T x_{n}\right), x_{n}\right\rangle+t_{n}^{q} c_{q}\left\|J_{E}^{p}\left(x_{n}-T x_{n}\right)\right\|^{q}\right)-\left\langle J_{E}^{p} x_{n}, x^{*}\right\rangle \\
& +t_{n}\left\langle J_{E}^{p}\left(x_{n}-T x_{n}\right), x^{*}\right\rangle+\frac{1}{p}\left\|x^{*}\right\|^{p} \\
= & \frac{1}{q}\left\|x_{n}\right\|^{p}-t_{n}\left\langle J_{E}^{p}\left(x_{n}-T x_{n}\right), x_{n}-x^{*}\right\rangle+\frac{t_{n}^{q} c_{q}}{q}\left\|J_{E}^{p}\left(x_{n}-T x_{n}\right)\right\|^{q}-\left\langle J_{E}^{p} x_{n}, x^{*}\right\rangle+\frac{1}{p}\left\|x^{*}\right\|^{p} \\
\leq & \frac{1}{q}\left\|x_{n}\right\|^{p}-t_{n} \frac{(1-\eta)}{2}\left\|x_{n}-T x_{n}\right\|^{p}+\frac{t_{n}^{q} c_{q}}{q}\left\|x_{n}-T x_{n}\right\|^{p}-\left\langle J_{E}^{p} x_{n}, x^{*}\right\rangle+\frac{1}{p}\left\|x^{*}\right\|^{p},
\end{aligned}
$$

which implies that

$$
\phi_{p}\left(y_{n}, x^{*}\right) \leq \phi_{p}\left(x_{n}, x^{*}\right)-t_{n}\left(\frac{(1-\eta)}{2}-t_{n}^{q-1} \frac{c_{q}}{q}\right)\left\|x_{n}-T x_{n}\right\|^{p} .
$$

Now, from (3.1) and (3.2), we derive

$$
\begin{aligned}
\phi_{p}\left(x_{n+1}, x^{*}\right) \leq & \alpha_{n} \phi_{p}\left(u, x^{*}\right)+\left(1-\alpha_{n}\right) \phi_{p}\left(y_{n}, x^{*}\right) \\
\leq & \alpha_{n} \phi_{p}\left(u, x^{*}\right)+\left(1-\alpha_{n}\right) \phi_{p}\left(x_{n}, x^{*}\right) \\
& -\left(1-\alpha_{n}\right) t_{n}\left(\frac{(1-\eta)}{2}-t_{n}^{q-1} \frac{c_{q}}{q}\right)\left\|(I-T) x_{n}\right\|^{p} .
\end{aligned}
$$

Since

$$
\frac{(1-\eta)}{2}-t_{n}^{q-1} \frac{c_{q}}{q}>0
$$

it follows that

$$
\phi_{p}\left(x_{n+1}, y^{*}\right) \leq+\alpha_{n} \phi_{p}\left(u, x^{*}\right)+\left(1-\alpha_{n}\right) \phi_{p}\left(x_{n}, x^{*}\right) .
$$

Now, we show that $\left\{\phi_{p}\left(x_{n}, x^{*}\right)\right\}$ is a bounded sequence. It suffices to show that $\phi_{p}\left(x_{n}, x^{*}\right) \leq M$ for all $n \geq 1$, where $M:=\max \left\{\phi_{p}\left(u, x^{*}\right), \phi_{p}\left(x_{0}, x^{*}\right)\right\}$. Note that if $n=0$, then $\phi_{p}\left(x_{0}, x^{*}\right) \leq M$. Assume that $\phi_{p}\left(x_{n}, x^{*}\right) \leq M$, for $n \geq 1$. Then

$$
\phi_{p}\left(x_{n+1}, x^{*}\right) \leq\left(1-\alpha_{n}\right) \phi_{p}\left(x_{n}, x^{*}\right)+\alpha_{n} \phi_{p}\left(u, x^{*}\right) \leq M .
$$

This shows that $\left\{\phi\left(x_{n}, x^{*}\right)\right\}$ is bounded and hence $\left\{x_{n}\right\}$ and $\left\{y_{n}\right\}$ are also bounded.

Theorem 3.2. Let $C$ be a nonempty, closed and convex subset of a p-uniformly convex and smooth real Banach space $E$. Let $\eta$ be in $(-\infty, 1)$. Let $T: C \rightarrow E$ be an $\eta$-demimetric mapping. Assume that $I-T$ is demiclosed at zero and $F(T) \neq \emptyset$. For arbitrary $x_{0}, u \in C$, define an iterative sequence $\left\{x_{n}\right\}$ by (3.1). Then, $\left\{x_{n}\right\}$ converges strongly to $\widehat{x}=\Pi_{F(T)} u$.

Proof. From Theorem 3.1, we know that $\left\{x_{n}\right\}$ is bounded. Take $\widehat{x}=\Pi_{F(T)} u$. Using (2.3), we get

$$
\left\langle J_{E}^{p} u-J_{E}^{p} \widehat{x}, z-\widehat{x}\right\rangle \leq 0, \forall z \in F(T)
$$


Now, from (2.5), (2.6), (2.7) and (3.1), we obtain

$$
\begin{aligned}
\phi_{p}\left(x_{n+1}, \widehat{x}\right) \leq & \phi_{p}\left(\left(J_{E}^{p}\right)^{-1}\left(\alpha_{n} J_{E}^{p} u+\left(1-\alpha_{n}\right) J_{E}^{p} y_{n}\right), \widehat{x}\right) \\
= & V_{p}\left(\alpha_{n} J_{E}^{p} u+\left(1-\alpha_{n}\right) J_{E}^{p} y_{n}, \widehat{x}\right) \\
= & V_{p}\left(\alpha_{n} J_{E}^{p} u+\left(1-\alpha_{n}\right) J_{E}^{p} y_{n}-\alpha_{n}\left(J_{E}^{p} u-J_{E}^{p} \widehat{x}\right), \widehat{x}\right) \\
& +\left\langle\alpha_{n}\left(J_{E}^{p} u-J_{E}^{p} \widehat{x}\right), x_{n+1}-\widehat{x}\right\rangle \\
= & V_{p}\left(\alpha_{n} J_{E}^{p} \widehat{x}+\left(1-\alpha_{n}\right) J_{E}^{p} y_{n}, \widehat{x}\right)+\alpha_{n}\left\langle J_{E}^{p} u-J_{E}^{p} \widehat{x}, x_{n+1}-\widehat{x}\right\rangle \\
= & \phi_{p}\left(\left(J_{E}^{p}\right)^{-1}\left(\alpha_{n} J_{E}^{p} \widehat{x}+\left(1-\alpha_{n}\right) J_{E}^{p} y_{n}\right), \widehat{x}\right) \\
& +\alpha_{n}\left\langle J_{E}^{p} u-J_{E}^{p} \widehat{x}, x_{n+1}-\widehat{x}\right\rangle \\
\leq & \alpha_{n} \phi_{p}(\widehat{x}, \widehat{x})+\left(1-\alpha_{n}\right) \phi_{p}\left(y_{n}, \widehat{x}\right)+\alpha_{n}\left\langle J_{E}^{p} u-J_{E}^{p} \widehat{x}, x_{n+1}-\widehat{x}\right\rangle \\
= & \left(1-\alpha_{n}\right) \phi_{p}\left(y_{n}, \widehat{x}\right)+\alpha_{n}\left\langle J_{E}^{p} u-J_{E}^{p} \widehat{x}, x_{n+1}-\widehat{x}\right\rangle \\
\leq & \left(1-\alpha_{n}\right) \phi_{p}\left(x_{n}, \widehat{x}\right)+\alpha_{n}\left\langle J_{E}^{p} u-J_{E}^{p} \widehat{x}, x_{n+1}-\widehat{x}\right\rangle \\
& -\left(1-\alpha_{n}\right) t_{n}\left(\frac{(1-\eta)}{2}-t_{n}^{q-1} \frac{c_{q}}{q}\right)\left\|x_{n}-T x_{n}\right\|^{p},
\end{aligned}
$$

and hence

$$
\begin{aligned}
\phi_{p}\left(x_{n+1}, \widehat{x}\right) \leq & \left(1-\alpha_{n}\right) \phi_{p}\left(x_{n}, \widehat{x}\right)+\alpha_{n}\left\langle J_{E}^{p} u-J_{E}^{p} \widehat{x}, x_{n}-\widehat{x}\right\rangle \\
& +\alpha_{n}\left\|J_{E}^{p} u-J_{E}^{p} \widehat{x}\right\| \cdot\left\|x_{n+1}-x_{n}\right\| \\
& -\left(1-\alpha_{n}\right) t_{n}\left(\frac{(1-\eta)}{2}-t_{n}^{q-1} \frac{c_{q}}{q}\right)\left\|(I-T) x_{n}\right\|^{p} .
\end{aligned}
$$

Therefore,

$$
\begin{aligned}
\phi_{p}\left(x_{n+1}, \widehat{x}\right) \leq & \left(1-\alpha_{n}\right) \phi_{p}\left(x_{n}, \widehat{x}\right)+\alpha_{n}\left\langle J_{E}^{p} u-J_{E}^{p} \widehat{x}, x_{n}-\widehat{x}\right\rangle \\
& +\alpha_{n}\left\|J_{E}^{p} u-J_{E}^{p} \widehat{x}\right\| .\left\|x_{n+1}-x_{n}\right\| .
\end{aligned}
$$

Next, we show that the sequence $\left\{\phi_{p}\left(x_{n}, \widehat{x}\right)\right\}$ converges strongly to zero. For this, we consider two possible cases on $\left\{\phi_{p}\left(x_{n}, \widehat{x}\right)\right\}$.

Case 1. Assume that there exists $n_{0} \in \mathbb{N}$ such that the sequence of real numbers $\left\{\phi_{p}\left(x_{n}, \widehat{x}\right)\right\}$ is decreasing for all $n \geq n_{0}$. It then follows that $\left\{\phi_{p}\left(x_{n}, \widehat{x}\right)\right\}$ is convergent. Since the sequences $\left\{x_{n}\right\}$ is bounded, we conclude from (3.4) and the fact that $\alpha_{n} \rightarrow 0$ that

$$
\lim _{n \rightarrow \infty}\left\|x_{n}-T x_{n}\right\|=0 \text {. }
$$

It follows from (3.1) that

$$
\left\|J_{E}^{p} y_{n}-J_{E}^{p} x_{n}\right\|=t_{n}\left\|x_{n}-T x_{n}\right\|^{p-1} \rightarrow 0,
$$

which together with the fact that $\left(J_{E}^{p}\right)^{-1}$ is uniformly continuous yields that

$$
\lim _{n \rightarrow \infty}\left\|y_{n}-x_{n}\right\|=0 \text {. }
$$

Furthermore, from (3.1) and the fact that $\alpha_{n} \rightarrow 0$ as $n \rightarrow \infty$, we have

$$
\begin{aligned}
\phi_{p}\left(x_{n+1}, y_{n}\right) & \leq \phi_{p}\left(\left(J_{E}^{p}\right)^{-1}\left(\alpha_{n} J_{E}^{p} u+\left(1-\alpha_{n}\right) J_{E}^{p} y_{n}\right), y_{n}\right) \\
& \leq \alpha_{n} \phi_{p}\left(u, y_{n}\right)+\left(1-\alpha_{n}\right) \phi\left(y_{n}, y_{n}\right) \rightarrow 0 \text { as } n \rightarrow \infty .
\end{aligned}
$$


By using Lemma 2.2, we have $x_{n+1}-y_{n} \rightarrow 0$ as $n \rightarrow \infty$. Using (3.6) yields

$$
\lim _{n \rightarrow \infty}\left\|x_{n+1}-x_{n}\right\|=0 \text {. }
$$

Since $E$ is uniformly convex, which implies that it is reflexive, and $\left\{x_{n}\right\}$ is bounded in $E$, we can find a subsequence $\left\{x_{n_{i}}\right\}$ of $\left\{x_{n}\right\}$, which converges weakly to $\bar{x}$ and

$$
\limsup _{n \rightarrow \infty}\left\langle J_{E}^{p} u-J_{E}^{p} \widehat{x}, x_{n}-\widehat{x}\right\rangle=\lim _{j \rightarrow \infty}\left\langle J_{E}^{p} u-J_{E}^{p} \widehat{x}, x_{n_{j}}-\widehat{x}\right\rangle .
$$

Furthermore, the fact that $I-T$ is demiclosed at zero yields that $\bar{x} \in F(T)$. Therefore, from (3.3) and (3.8), we obtain

$$
\begin{aligned}
\limsup _{n \rightarrow \infty}\left\langle J_{E}^{p} u-J_{E}^{p} \widehat{x}, x_{n}-\widehat{x}\right\rangle & =\lim _{j \rightarrow \infty}\left\langle x_{n_{j}}-\widehat{x}, J_{E}^{p} u-J_{E}^{p} \widehat{x}\right\rangle \\
& =\left\langle J_{E}^{p} u-J_{E}^{p} \widehat{x}, \bar{x}-\widehat{x}\right\rangle \leq 0 .
\end{aligned}
$$

In view of (3.5), (3.7), (3.9) and Lemma 2.4, we conclude that $\phi_{p}\left(x_{n}, \widehat{x}\right)$ converges strongly to zero as $n \rightarrow \infty$. Therefore, $\left\{x_{n}\right\}$ converges strongly to $\widehat{x}=\Pi_{F(T)} u$.

Case 2. Assume that there exists a subsequence $\left\{\phi_{p}\left(x_{n_{i}}, \widehat{x}\right)\right\}$ of $\left\{\phi_{p}\left(x_{n}, \widehat{x}\right)\right\}$ such that $\phi_{p}\left(x_{n_{i}}, \widehat{x}\right)<$ $\phi_{p}\left(x_{n_{i}+1}, \widehat{x}\right)$ for all $i \geq 0$. In view of Lemma 2.3, we can define a nondecreasing sequence $\left\{m_{k}\right\} \subset \mathbb{N}$ such that $m_{k} \rightarrow \infty$ as $k \rightarrow \infty$ and $\phi\left(x_{m_{k}}, \widehat{x}\right) \leq \phi\left(x_{m_{k}+1}, \widehat{x}\right)$, and $\phi\left(x_{k}, \widehat{x}\right) \leq \phi\left(x_{m_{k}+1}, \widehat{x}\right)$ for all $k \in \mathbb{N}$. Since the sequences $\left\{x_{m_{k}}\right\}$ is bounded, it follows from (3.4) and the methods in Case 1 that $\left\|x_{m_{k}}-T x_{m_{k}}\right\| \rightarrow 0,\left\|x_{m_{k}+1}-x_{m_{k}}\right\| \rightarrow 0$ as $k \rightarrow \infty$ and

$$
\limsup _{k \rightarrow \infty}\left\langle J_{E}^{p} u-J_{E}^{p} \widehat{x}, x_{m_{k}}-\widehat{x}\right\rangle \leq 0 .
$$

Finally, making use of $\phi\left(x_{m_{k}}, \widehat{x}\right) \leq \phi_{p}\left(x_{m_{k}+1}, \widehat{x}\right)$ for all $k \in \mathbb{N}$, and rearranging terms in (3.5), we derive

$$
\begin{aligned}
\left.\alpha_{m_{k}} \phi_{(} x_{m_{k}}, \widehat{x}\right) \leq & \left.\phi_{p}\left(x_{m_{k}}, \widehat{x}\right)-\phi_{p}\left(x_{m_{k}+1}, \widehat{x}\right)+\alpha_{m_{k}}\left\langle J_{E}^{p} u-J_{E}^{p} \widehat{x}, x_{m_{k}}-\widehat{x}\right)\right\rangle \\
& +\alpha_{m_{k}}\left\|J_{E}^{p} u-J_{E}^{p} \widehat{x}\right\| \times\left\|x_{m_{k}+1}-x_{m_{k}}\right\| .
\end{aligned}
$$

Dividing by $\alpha_{m_{k}}$ and passing to the limit as $k \rightarrow \infty$ in the resulting inequality, we obtain $\phi_{p}\left(x_{m_{k}}, \widehat{x}\right) \rightarrow 0$. Hence, $\phi_{p}\left(x_{m_{k}+1}, \widehat{x}\right) \rightarrow 0$ as $k \rightarrow \infty$. Since $\phi_{p}\left(x_{k}, \widehat{x}\right) \leq \phi_{p}\left(x_{m_{k}+1}, \widehat{x}\right)$, we find that $\phi_{p}\left(x_{k}, \widehat{x}\right) \rightarrow 0$ as $k \rightarrow \infty$ and hence $x_{k} \rightarrow \widehat{x}$ as $k \rightarrow \infty$. Therefore, we have shown in both cases that the sequence $\left\{x_{n}\right\}$ generated by (3.1) converges strongly to $\widehat{x} \in F(T)$. This completes the proof of this theorem.

If, in Theorem 3.2, $C=E$, then $\Pi_{C}$ is reduced to the identity mapping on $E$. We get the following corollary.

Corollary 3.1. Let $E$ be a p-uniformly convex and smooth real Banach space. Let $T: E \rightarrow E$ be an $\eta$-demimetric mapping. Assume that $I-T$ is demiclosed at zero and $F(T) \neq \emptyset$. For arbitrary $x_{0}, u \in E$, define an iterative sequence by

$$
\left\{\begin{array}{l}
y_{n}=\left(J_{E}^{p}\right)^{-1}\left[J_{E}^{p} x_{n}-t_{n} J_{E}^{p}\left(x_{n}-T x_{n}\right)\right] \\
x_{n+1}=\left(J_{E}^{p}\right)^{-1}\left[\alpha_{n} J_{E}^{p} u+\left(1-\alpha_{n}\right) J_{E}^{p} y_{n}\right],
\end{array}\right.
$$

where $0<\delta \leq t_{n} \leq \gamma<\left(\frac{(1-\eta) q}{2 c_{q}}\right)^{\frac{1}{q-1}}$, for all $n \geq 0$ and $c_{q}$ is the constant in (2.1). Then, $\left\{x_{n}\right\}$ converges strongly to the minimum norm $\widehat{x}$ of $F(T)$.

If, in Theorem 3.2, $E=H$, a real Hilbert spaces, then $p=2$. Hence $J_{E}^{p}$ is the identity mapping and $c_{q}=1$. Thus, we get the following corollary. 
Corollary 3.2. Let $C$ be a nonempty, closed and convex subset of a real Hilbert space $H$. Let $\eta$ be in $(-\infty, 1)$. Let $T: C \rightarrow H$ be an $\eta$-demimetric mapping. Assume that $I-T$ is demiclosed at zero and $F(T) \neq \emptyset$. For arbitrary $x_{0}, u \in C$, define an iterative sequence $\left\{x_{n}\right\}$ by

$$
\left\{\begin{array}{l}
y_{n}=x_{n}-t_{n}\left(x_{n}-T x_{n}\right), \\
x_{n+1}=P_{C}\left[\alpha_{n} u+\left(1-\alpha_{n}\right) y_{n}\right], n \geq 1,
\end{array}\right.
$$

where $0<\delta \leq t_{n} \leq \gamma<(1-\eta)$, for all $n \geq 0$. Then, $\left\{x_{n}\right\}$ converges strongly to an element $\widehat{x}=P_{F(T)}(u)$.

If, in Corollary 3.2, $T$ is a self-mapping, then $P_{C}$ is reduced to the identity mapping on $C$. Hence, we get the following corollary.

Corollary 3.3. Let $C$ be a nonempty, closed and convex subset of a real Hilbert space $H$. Let $\eta$ be in $(-\infty, 1)$. Let $T: C \rightarrow C$ be an $\eta$-demimetric mapping. Assume that $I-T$ is demiclosed at zero and $F(T) \neq \emptyset$. For arbitrary $x_{0}, u \in C$, define an iterative sequence $\left\{x_{n}\right\}$ by

$$
\left\{\begin{array}{l}
y_{n}=x_{n}-t_{n}\left(x_{n}-T x_{n}\right), \\
x_{n+1}=\alpha_{n} u+\left(1-\alpha_{n}\right) y_{n}, n \geq 1,
\end{array}\right.
$$

where $0<\delta \leq t_{n} \leq \gamma<(1-\eta)$, for all $n \geq 0$. Then, $\left\{x_{n}\right\}$ converges strongly to an element $\widehat{x}=P_{F(T)}(u)$.

\section{Applications}

In this section, we present some applications of our results in the context of convex and nonlinear analysis problems.

The following lemmas are needed.

Lemma 4.1. [23] Let $H$ be a real Hilbert space and let $C$ be a nonempty, closed and convex subset of $H$. Let $T: C \rightarrow H$ be a $k$-strictly pseudo-contraction. If $x_{n} \rightarrow z$ and $x_{n}-T x_{n} \rightarrow 0$ as $n \rightarrow \infty$, then $z \in F(T)$, that is, $I-T$ is demiclosed at zero.

Lemma 4.2. [24] Let $H$ be a real Hilbert space and let $C$ be a nonempty, closed and convex subset of $H$. Let $T: C \rightarrow C$ be generalized hybrid mapping. If $x_{n} \rightarrow z$ and $x_{n}-T x_{n} \rightarrow 0$ as $n \rightarrow \infty$, then $z \in F(T)$.

Lemma 4.3. [9] Let $C$ be a nonempty, closed and convex subsets of a uniformly smooth and strictly convex Banach space $E$. Let $P_{C}$ be the metric projection from $E$ onto $C$. If $x_{n} \rightarrow z$ and $x_{n}-P_{C} x_{n} \rightarrow 0$ as $n \rightarrow \infty$, then $z \in F\left(P_{C}\right)$, i.e., $I-P_{C}$ is demiclosed at zero.

Theorem 4.1. Let $C$ be nonempty, closed and convex subset of a real Hilbert space H. Let $T: C \rightarrow C$ be a k-strict pseudocontractive mapping with $F(T) \neq \emptyset$. For arbitrary $x_{0}, u \in C$, define an iterative sequence $\left\{x_{n}\right\}$ by

$$
\left\{\begin{array}{l}
y_{n}=x_{n}-t_{n}\left(x_{n}-T x_{n}\right), \\
x_{n+1}=\alpha_{n} u+\left(1-\alpha_{n}\right) y_{n}, n \geq 1,
\end{array}\right.
$$

where $0<\delta \leq t_{n} \leq \gamma<(1-k)$, for all $n \geq 0$. Then, $\left\{x_{n}\right\}$ converges strongly to $\widehat{x}=P_{F(T)}(u)$.

Proof. Note that $T$ is $k$-demimetric and $I-T$ is demiclosed at zero. From Corollary 3.3, we get the desired conclusion immediately. 
If, in Corollary 3.3, $T$ is an $(\alpha, \beta)$-generalized hybrid mapping, then we have the following result.

Theorem 4.2. Let $C$ be nonempty, closed and convex subset of a real Hilbert space $H$. Let $T: C \rightarrow C$ be an $(\alpha, \beta)$ generalized hybrid mapping with $F(T) \neq \emptyset$. For arbitrary $x_{0}, u \in C$, define an iterative sequence $\left\{x_{n}\right\}$ by

$$
\left\{\begin{array}{l}
y_{n}=x_{n}-t_{n}\left(x_{n}-T x_{n}\right), \\
x_{n+1}=\alpha_{n} u+\left(1-\alpha_{n}\right) y_{n}, n \geq 1,
\end{array}\right.
$$

where $0<\delta \leq t_{n} \leq \gamma<1$, for all $n \geq 0$. Then, $\left\{x_{n}\right\}$ converges strongly to $\widehat{x}=P_{F(T)}(u)$.

Proof. Note that $T$ is 0 -demimetric. From Lemma 4.2, we have that $I-T$ is demiclosed. Using Corollary 3.3, we have the desired conclusion immediately.

If, in Corollary 3.1, $T=P_{C}$, where $C$ closed and convex subsets of a $p$-uniformly convex Banach space $E$, then we get the following result.

Theorem 4.3. Let $C$ be nonempty, closed and convex subset of a real p-uniformly convex Banach space $E$. Let $P_{C}: E \rightarrow C$ be the projection mapping. For arbitrary $x_{0}, u \in E$, define an iterative sequence by

$$
\left\{\begin{array}{l}
y_{n}=\left(J_{E}^{p}\right)^{-1}\left[J_{E}^{p} x_{n}-t_{n} J_{E}^{p}\left(x_{n}-P_{C} x_{n}\right)\right], \\
x_{n+1}=\left(J_{E}^{p}\right)^{-1}\left[\alpha_{n} J_{E}^{p} u+\left(1-\alpha_{n}\right) J_{E}^{p} y_{n}\right],
\end{array}\right.
$$

where $0<\delta \leq t_{n} \leq \gamma<\left(\frac{q}{c_{q}}\right)^{\frac{1}{q-1}}$, for all $n \geq 0$ and $c_{q}$ is the constant in (2.1). Then, $\left\{x_{n}\right\}$ converges strongly to $\widehat{x}=P_{C}(u)$.

Proof. Take $T:=P_{C}$. Then, $T$ is $(-1)$-demimetric and by Lemma 4.3, we have that $(I-T)$ is demiclosed at zero. From Corollary 3.1, we have the desired conclusion easily.

Furthermore, from Theorem 3.2, we also have the following strong convergence result for finding the zero of a maximal monotone operator in Banach spaces.

Theorem 4.4. Let $C$ be a nonempty, closed and convex subset of a p-uniformly convex and smooth real Banach space $E$. Let $A$ be a maximal monotone mapping of $E$ into $2^{E^{*}}$ and let $J_{\lambda}^{A}=\left(I+\lambda J_{E}^{-1} A\right)$ be the resolvent of $A$ with $N(A) \neq \emptyset$. For arbitrary $x_{0}, u \in C$, define an iterative sequence by

$$
\left\{\begin{array}{l}
y_{n}=\left(J_{E}^{p}\right)^{-1}\left[J_{E}^{p} x_{n}-t_{n} J_{E}^{p}\left(x_{n}-J_{\lambda}^{A} x_{n}\right)\right] \\
x_{n+1}=\prod_{C} J_{p}^{-1}\left[\alpha_{n} J_{p} u+\left(1-\alpha_{n}\right) J_{p} y_{n}\right]
\end{array}\right.
$$

where $0<\delta \leq t_{n} \leq \gamma<\left(\frac{q}{c_{q}}\right)^{\frac{1}{q-1}}$, for all $n \geq 0$ and $c_{q}$ is the constant in (2.1). Then, $\left\{x_{n}\right\}$ converges strongly to $\widehat{x} \in N(A)$.

Proof. Note that $T:=J_{\lambda}^{A}$ is nonexpansive and (-1)-demimetric. Furthermore, from [13, Theorem 4.6], we have that $\left(I-J_{\lambda}^{A}\right)$ is demiclosed at zero. Using Theorem 3.2, we obtain the desired conclusion immediately.

Conclusions. Theorem 3.2 provides an algorithm which converge strongly to fixed points of $\eta$-demimetric mappings in the setting of Banach spaces. Theorem 3.2 improves the results announced by Hojo and Takahashi [13] in the sense that our algorithm does not require the 
involvement of computation of $C_{n}$ and $Q_{n}$ for each iterative setp. Our results provide affirmative answers to the question raised in Section 1.

\section{REFERENCES}

[1] N. Shahzad and H. Zegeye, The split common fixed point problem for $\eta$-demimetric mappings in Banach spaces, J. Nonlinear Convex Anal. 21 (2020), 2589-2603.

[2] W. Takahashi, The split common fixed point problem and the shrinking projection method in Banach spaces, J. Convex Anal. 24 (2017), 1015-1028.

[3] W. Takahashi, Nonlinear functional analysis. Fixed point theory and its applications, Yokohama Publishers, Yokohama, 2000.

[4] H. Zegeye, N. Shahzad, Algorithms for solutions of variational inequalities in the set of common fixed points of finite family of $\lambda$-strictly pseudocontractive mappings, Numer. Funct. Anal. Optim. 36 (2015), 799-816.

[5] I. Cioranescu, Geometry of Banach Spaces, Duality Mappings and Nonlinear Problems, Kluwer, Dordrecht, 1990.

[6] N. Shahzad and H. Zegeye, Iterative algorithm for a common fixed point of two mono-pseudocontractive mappings in Banach spaces, J. Nonlinear Sci. Appl. 10 (2017), 4799-4811.

[7] E. Zeidler, Nonlinear functional analysis, vol. 3. Springer Verlag, New York, 1984.

[8] W. Takahashi, Convex Analysis and Approximation of Fixed Points, Yokohama Publishers, Yokohama, 2000 (Japanese).

[9] H. Zegeye, O. A. Boikanyon, Halpern-type method for non-self nonexpansive mappings in Banach spaces, Linear Nonlinear Anal. 4 (2018), 145-156.

[10] C. E. Chidume, S. Măruşter, Iterative methods for the computation of fixed points of demicontractive mappings, J. Comput. Appl. Math. 234 (2010), 861-882.

[11] H. Zegeye, N. Shahzad, M. A. Alghamdi, Iterative methods for equilibrium and fixed point of relatively k-strict pseudocontractive mapping problems in Banach spaces, J. Nonlinear Convex Anal. 18 (2017), 15911608.

[12] W. Takahashi, C.-F. Wen, J.-C. Yao, Strong convergence theorem by shrinking projection method for new nonlinear mappings in Banach spaces and applications, Optimization 66 (2017), 609-621.

[13] M. Hojo, W. Takahashi, Strong convergence theorems by hybrid methods for demimetric mappings in Banach spaces, J. Nonlinear Convex Anal. 17 (2016), 1333-1344.

[14] J. Lindenstrauss, L. Tzafriri, Classical Banach Spaces II, Springer, Berlin, 1979.

[15] H. K. Xu, Inequalities in Banach spaces with applications, Nonlinear Anal. 16 (1991), 1127-1138.

[16] S. Kamimura, W. Takahashi, Strong convergence of proximal-type algorithm in a Banach space, SIAM J. Optim. 13 (2002), 938-945.

[17] L.M. Bregman, The relaxation method for finding the common point of convex sets and its application to the solution of problems in convex programming, USSR Comput. Math. Math. Phys. 7 (1967), 200-217.

[18] V. Martin-Marquez, S. Reich, S. Sabach, Iterative methods for approximating fixed points of Bregman nonexpansive operators, Discrete Contin. Dyn. Syst. Ser. S 6 (2013), 1043-1063.

[19] F. Kohsaka, W. Takahashi, Proximal point algorithms with Bregman functions in Banach spaces, J. Nonlinear Convex Anal. 6 (2005), 505-523.

[20] R. P. Phelps, Convex Functions, Monotone Operators and Differentiability, Second edition. Lecture Notes in Mathematics, 1364, Springer-Verlag, Berlin, 1993.

[21] P. E. Mainge, Strong convergence of projected subgradient methods for nonsmooth and non- strictly convex minimization, Set-Valued Anal. 16 (2008), 899-912.

[22] H. K. Xu, Another control condition in an iterative method for nonexpansive mappings, Bull. Austral. Math. Soc. 65 (2002), 109-113

[23] G. Marino, H. K. Xu, Weak and strong convergence theorems for strict pseudo-contractions in Hilbert spaces, J. Math. Anal. Appl. 329 (2007), 336-346.

[24] P. Kocourck, W. Takahashi, J.-C. Yao, Fixed point theorems and weak convergence theorem for generalized hybrid mappings in Hilbert spaces, Taiwanese J. Math. 14 (2010), 2497-2511. 